\title{
DESAFIOS DO PROCESSO EDUCACIONAL EM AMBIENTES VIRTUAIS DE APRENDIZAGEM DA FACULDADE ESTÁCIO DO AMAPÁ
}

\section{ARTIGO ORIGINAL}

THURY, Ana Paula de Souza Rocha ${ }^{1}$

OLIVEIRA, Diney Adriana Nogueira de ${ }^{2}$

THURY, Ana Paula de Souza Rocha. OLIVEIRA, Diney Adriana Nogueira de. Desafios do processo educacional em ambientes virtuais de aprendizagem da Faculdade Estácio do Amapá. Revista Científica Multidisciplinar Núcleo do Conhecimento. Ano 05, Ed. 07, Vol. 04, pp. 196-221. Julho de 2020. ISSN: 2448-0959, Link de acesso: https://www.nucleodoconhecimento.com.br/educacao/desafios-doprocesso

\section{RESUMO}

Este artigo se refere ao tema Educação à Distância, com o propósito de demonstrar a sua origem, desde as primeiras tecnologias, discorrendo sobre seus aspectos positivos e negativos, com fundamentação teórica sobre a sua história. Nesse sentido, serão ressaltados os impactos sobre a vida do homem, em seus diferentes aspectos e fenômenos, através de uma linha do tempo que demonstra cada momento da $E A D$, por meio das interferências políticas e seu crescimento, no Brasil e no mundo. Assim esta investigação verificará o acesso ao ambiente virtual (SIA) da Faculdade Estácio do Amapá, e seus impactos sobre os alunos presentes na instituição, que trazem mudanças e transformações. Dessa forma, buscar-se-á descobrir como acontece a

\footnotetext{
${ }^{1}$ Graduação em Pedagogia.

2 Orientador. Doutorado em Comunicação Social. Mestrado em Comunicação Social. Especialização em Desarollo Turístico. Especialização em Administração Em Turismo. Graduação em Bacharel Em Turismo.
} 
educação à distância, desde os $20 \%$ obrigatório nos cursos presenciais, perpassando por sua trajetória, até se chegar aos dias atuais. E ao final desta pesquisa, será possível compreender o resultado de seus impactos sobre os estudantes, para melhor entendimento do tema no qual se refere à modalidade de estudo a distância. A pesquisa de campo do trabalho de conclusão de curso ocorreu na Faculdade Estácio do Amapá, com cerca de 50 alunos ali presentes, no qual foi feita através de entrevistas, com abordagem livre e espontânea na biblioteca, na lanchonete e no pátio da faculdade. Foi usada a metodologia quali-quantitativa, em que o questionário utilizado na entrevista teve como objetivo, investigar tanto a opinião dos alunos, quanto o quantitativo dessas opiniões, sendo elas positivas ou negativas sobre o Sistema de Informações acadêmicas da Faculdade Estácio do Amapá e os 20\% das disciplinas de Educação à distância que são obrigatórios. As entrevistas duraram entre 2 a 5 minutos, e todas foram gravadas.

Palavras-Chave: Tecnologia, ensino superior, educação à distância.

\section{INTRODUÇÃO}

O presente estudo se debruça sobre a temática da educação a distância na Faculdade Estácio do Amapá, no município de Macapá, visando entender as dificuldades existentes na vida acadêmica dos alunos, no que diz respeito às disciplinas à distância. Essa pesquisa é importante, porque ela vai demonstrar as reais dificuldades dos alunos da Faculdade Estácio, diante da plataforma EAD, ajudando assim a faculdade a entender melhor a situação dos seus alunos. Dentre os diversos autores consultados para elaboração da pesquisa destacam-se: Mendes (2007); Vinha (2007); Litto e Formiga (2009); Ribeiro (2010); Kenski (2012); Castilho (2014).

O trabalho está dividido em três partes. Na primeira se traça o panorama geral sobre o surgimento das tecnologias de informações e comunicações (TICs), assim como o seu significado para o homem e suas transformações na utilização individual, na educação e no trabalho; No segundo tópico se discorre sobre a educação à distância no ensino superior atual. $O$ tópico final trás os resultados da análise sobre os impactos que os alunos da Faculdade Estácio do Amapá enfrentam com a plataforma digital do 
sistema do aluno, realizada com 50 alunos dos cursos de direito, engenharia civil, ciências contábeis, pedagogia e administração, dos seguintes semestres: $1^{\circ}, 2^{\circ}, 4^{\circ}$, $5^{\circ}, 6^{\circ}, 7^{\circ}, 8^{\circ}, 9^{\circ}$ e $10^{\circ}$.

Definiu-se como problema da investigação que concebeu este trabalho a seguinte indagação: Quais impactos os alunos da Faculdade Estácio do Amapá enfrentam ao serem inseridos na plataforma digital do sistema do aluno? Que teve como hipótese básica para o problema da pesquisa que: os impactos ocorrem porque esses alunos são de uma geração divergente a atual, e isso faz com que seja necessário um tempo de adaptação, e também porque muitos alunos não possuem condições financeiras de ter internet em casa, ou pelo fato de não se ter o conhecimento e o tempo necessário para o estudo à distância.

\section{O SURGIMENTO DAS TECNOLOGIAS DE INFORMAÇÕES E COMUNICAÇÕES (TICS), ASSIM COMO O SEU SIGNIFICADO PARA O HOMEM E SUAS TRANSFORMAÇÕES NA UTILIZAÇÃO INDIVIDUAL, NA EDUCAÇÃO E NO TRABALHO}

\subsection{O SURGIMENTO DA TECNOLOGIA}

A tecnologia sempre esteve presente na vida do ser humano, por isso, o surgimento da tecnologia está interligado ao surgimento do ser humano, pois a tecnologia é qualquer instrumento criado pelo homem, para facilitar seu dia-a-dia, desde os primórdios da era humana. No início, as primeiras criações supriam necessidades do homem, e assim acontece nos dias de hoje, comparadas as tecnologias.

Desde esfregar uma rocha na outra para se obter fogo, na intenção de amenizar o frio, até se criar um celular onde se pode trabalhar, estudar, e conversar com amigos e familiares, foi um processo longo, que durou séculos. Nesse período, muitas tecnologias foram criadas, pois à medida que o tempo passa, o mundo se modifica, e o homem também sofre mudanças e com ele suas necessidades, por isso ele sempre 
está criando novas tecnologias para suprir suas novas necessidades do dia-a-dia. Diante disso, Alves destaca que:

A relação entre o homem com a natureza foi sempre mediada pela tecnologia, embora esta mediação seja mais marcante na sociedade contemporânea, pois o impulso tecnológico do século XX marca as instituições sociais e interfere em todos os setores da atividade humana. (ALVES, 2009, p. 18)

Ademais, tal relação se manifesta a cada período histórico. No entanto, a partir do século XX, no período pós Segunda Guerra Mundial, essa relação entre o homem e a tecnologia se torna cada vez mais relevante, onde em algumas situações a tecnologia pode substituir o ser humano, por exemplo, em algumas tarefas domésticas.

Contudo, a tecnologia se expandiu não só nos setores domésticos e particulares do homem, mas também nas atividades coletivas manifestadas no estudo e no trabalho, onde as tecnologias, ao passar do tempo, apresentaram formas e maneiras da humanidade atuar nessas atividades, seja pelo estudo em um livro ou em um youtube, ou pelo trabalho em fábricas manualmente ou em empresas em um escritório, atrás de um computador.

Todavia, a tecnologia é criada pela inteligência humana, de querer naturalmente facilitar a vida, tornando-a mais simples e menos cansativa, de fato, máquinas foram criadas para reduzir o tempo de trabalho manual, em fábricas, com o intuito de diminuir o cansaço do trabalhador e aumentar o desempenho do mesmo.

Como também, Hara (2011) ressalta que esse tempo poupado pode ser empregado em estudos, tarefas domésticas ou lazer. Assim como outras tecnologias, do dia-a-dia do homem, que servem para facilitar a vida, como por exemplo, o controle remoto, que tem como objetivo, trocar o canal da TV sem que o indivíduo precise se levantar do sofá e efetivar tal atividade. 


\subsection{O CONCEITO DAS (TICS)}

Mesmo a tecnologia, sendo algo tão surpreendente e espetacular na vida do homem, em que se renova de geração em geração, não é fácil dar um conceito a mesma, pois está sempre em constante mudança, deixando saudade do que passou na história, e causando ansiedade para as novas tecnologias do futuro, que o homem será capaz de criar.

Conforme Castilho (2014), a etimologia da tecnologia é construída da seguinte forma, é uma palavra composta por duas, que são: "tecnhos" que significa o processo de fazer algo, e "logia" que significa o entendimento sobre algo, logo a tecnologia é o conhecimento de fazer algo ou a manipulação da natureza para finalidades humanas. Ou seja, a tecnologia é criada pelo homem, de acordo com as necessidades do mesmo, com o proposito de executar tarefas que o homem realizaria. Porém, a tecnologia faz com mais agilidade e rapidez, facilitando a vida do homem.

De acordo com Kenski (2012), a tecnologia virtual é ao mesmo tempo imaterial e a sua matéria prima é a informação, e com base na informação surgiram as Tecnologias de Informações e Comunicações (TICs), através da necessidade da liberdade de expressão, ou registrar experiências, e assim foram criados os meios de comunicação, que são espaços exclusivos para comunicar e informar notícias e experiências, onde vários grupos interagem em tempo real ou não.

\subsubsection{AS CARACTERÍSTICAS DAS (TICS)}

As tecnologias sempre tiveram suma importância na vida do homem, sendo assim, passaram por muitas fases, na sua linha do tempo, pois as primeiras tecnologias, tinham como características, suprir as necessidades naturais do homem, com o passar do tempo, as tecnologias passaram a ter uma importância significativa para a guerra, onde eram restritas para líderes de estados. Logo após o fim da guerra, a tecnologia passou a ter objetivos voltados à informação e comunicação. 
Portanto, segundo Castills (2003) apud Castilho (2014) as tecnologias são caracterizadas pelo seu alcance global, pela interação de todos os meios de comunicação e pela interatividade que está em constante mudança. Isso mostra que essas tecnologias, se desenvolveram de maneira rápida, e os avanços dessas tecnologias que a inteligência humana foi capaz de criar foram de enorme importância para a humanidade.

Com isso, foram criadas as primeiras tecnologias de informação, como o telefone, o rádio, a televisão e o computador e tudo isso foi se modernizando com o decorrer das décadas, com estudos e projetos, tudo foi acontecendo com uma velocidade imensurável. Como frisa Castilho (2014), a tecnologia de informação e comunicação é caracterizada, principalmente pela sua simulação, virtualidade, acessibilidade e também pela superabundância e diversidade de informação. Logo, todas essas características, se espalharam por todas as atividades do homem, até chegar à atualidade, em que o modo de viver se torna, segundo a afirmativa de Castilho (2014, p. 33) "a era dominada pelo virtual".

\subsection{A UTILIZAÇÃO DAS (TICS) PELO HOMEM}

As utilizações das tecnologias para as diversas atividades cotidianas são comuns, tanto para atividades individuais quanto coletivas. Como demonstrado por Santos (2014), as tecnologias fazem parte da vida do homem, em casa, no trabalho, na escola, na diversão e na comunicação. Essa utilização ocorre por meio de redes sociais através de aplicativos. A utilização das tecnologias pelo homem vai mudando de acordo com as décadas e épocas, onde as tecnologias novas vão ganhando espaço e as antigas vão ficando para trás.

As tecnologias são utilizadas por muito tempo, como o exemplo da música, em que antigamente se utilizavam, tecnologias como vídeo cassete, disco de vinil, e o CD, porém essas tecnologias ficaram para trás e as músicas digitais ganharam espaço, mas atualmente, após muitos anos, as tecnologias mais antigas estão voltando para o mercado, com a nostalgia, essas relíquias que fizeram tanto sucesso e marcaram décadas, se agrega a essa nova geração. Assim, são as tecnologias, podem passar 
décadas sendo útil ao homem, ou podem deixar de ser útil ao homem, e com isso podem ser esquecidas para sempre.

\subsubsection{O USO DAS (TICS) NA EDUCAÇÃO}

Segundo Mc Luhan (1970, apud Kenski, 2012) as tecnologias se tornam invisíveis à medida que se tornam familiares. $E$ isso ocorre a partir do momento em que as pessoas aprendem a usar essas tecnologias, que consequentemente deixam de ter esse nome, e passam a ser apenas mais um objeto de uso do homem. Esse objeto se torna banal pelo fato de ser utilizado continuamente no dia-a-dia, ele vai deixando de ser inovador.

Nas escolas e faculdades os meios tecnológicos, mais utilizados pelos professores é o data-show, o notebook, o celular e a internet, esses meios são utilizados para a elaboração de plano de aula, a comunicação com o aluno, e a apresentação da aula. Já os alunos fazem uso dessas tecnologias (com exceção do data show), para estudar, revisar as matérias, interagir com professores e colegas de classe, o que facilita a comunicação e a compreensão do que está sendo estudado.

As mudanças contemporâneas que acontecem por meio das redes sociais que transformam as relações com o saber, caracterizam-se, pela forma avançada e pela interação mútua que elas oferecem, de modo, que se encaixam perfeitamente, na contribuição com a educação, tendo como passar e receber informações em tempo real, o que ajuda, a fazer com que o conhecimento seja compartilhado. Tudo isso ocorre para que o aprendizado transcorra cada vez mais de maneira independente.

Porém essas tecnologias podem trazer problemas. Sendo assim, de acordo Kenski (2012), as máquinas tecnológicas podem adquirir problemas técnicos, que fazem com que se percam arquivos e documentos salvos na própria memória interna ou no pendrive ou cartão de memória, por meio de vírus que danificam arquivos, seja no computador, seja no notebook ou telefone, assim como também os problemas com hackers, que invadem as máquinas e apagam informações, ou espionam o que está sendo acessado ou guardado na máquina. 
Enfim, nesta geração, de informação e comunicação, os jovens se destacam pela facilidade de compreensão e entendimento, de cada tecnologia digital, que é lançada a cada instante. Para os adultos, acaba-se tendo certa dificuldade em lidar com essas inovações, pois esses adultos são de fato, de uma geração discrepante a contemporaneidade, e isso também se reflete na educação, onde os alunos mais jovens utilizam as tecnologias de maneira rápida e de modo eficaz, enquanto os adultos demoram um tempo maior para entender como funciona aquela determinada tecnologia.

\subsubsection{O USO DAS (TICS) NO TRABALHO}

Desde o início da informatização, as empresas correm contra o tempo, para se manterem sempre atualizadas, começando pela computação, seguindo pela informática, até chegar à internet, onde se junta o computador, a informação e a comunicação, através da internet, para se ter a TIC, inserida no trabalho.

Com isso, ocorreram mudanças onde tudo parecia esteticamente perfeito, pois as empresas estavam trocando o trabalho manual, pelo trabalho intelectual, porém essa corrida contra o tempo sobrecarregava os trabalhadores, aumentava o desemprego e fazia com que as empresas entrassem em um ritmo de competição insaciável. Além disso, Vinha (2007, p.47) complementa que "dentro das relações sociais de produção, a busca de maior produtividade do trabalho por meio das inovações tecnológicas e reestruturações produtivas sempre foi uma pressão institucional do capitalismo".

Com base na fala do autor, nota-se que as empresas precisam fazer uso de tecnologias, por isso necessita de trabalhadores com capacitações nessas tecnologias, por esse fato muitos trabalhadores perderam o emprego. A partir de então, esses trabalhadores que perderam seus empregos e os jovens que ainda estavam à procura de emprego, começaram a procurar cursos e capacitações em tecnologias, para que assim houvesse especializações tecnológicas para que fossem inseridos no mercado de trabalho. Nesse contexto, Vinha destaca que: 
Ocorreram profundas transformações na organização do trabalho no nível das empresas, com a expansão das multinacionais, a utilização intensiva de tecnologias de informação, a mobilidade no trabalho, aumento de concorrência, altas taxas de desemprego, etc. (VINHA, 2007, p. 49)

Sendo assim, as tecnologias de informações e comunicações trouxeram consigo, muitas dificuldades, por ser um novo modelo de trabalho e diferente de tudo aquilo que se tinha antes. Porém, depois que passou essa fase de adaptação, surgiu muitas propostas e projetos tecnológicos no trabalho, até chegar aos dias atuais, onde já se tem empresas que nasceram na era da informação e são totalmente tecnológicas. $E$ isso se deve também ao fato do acesso a câmeras, softwares de edição e plataformas de difusão por serem facilitadores pela escalabilidade de produtos no mercado. (SOUZA; GIGLO, 2015).

Como, por exemplo, o Uber, que é um aplicativo digital, e necessita de informações dos usuários, como nome, telefone e localidade, e funcionam apenas através da internet. Além de se ter a opção da comunicação entre o usuário passageiro e o usuário motorista por meio de mensagens. E se tem o exemplo de empresas que não foram construídas na era digital, mas se atualizam para não perder clientes e a popularidade, como o Banco do Brasil, que hoje tem seu aplicativo, que serve para facilitar a vida do seu cliente.

\subsection{AS TRANSFORMAÇÕES DAS (TICS) SOBRE A VIDA DO HOMEM}

A sociedade passa por muitas modificações com o decorrer do tempo, ela vai se modernizando e se adaptando a cada mudança, do jeito de pensar, de se vestir, de se falar e também nas músicas, nos problemas discutidos, no estudo, no trabalho, enfim, são muitos os aspectos que sofrem transformações na sociedade. Sendo assim, as tecnologias inseridas na sociedade, também sofrem por mudanças, pois fazem parte da vida do ser humano.

Com isso Castilho (2014) discorre que a evolução da tecnologia define mudanças na sociedade, assim como em todas as suas camadas. Na atualidade, conhecida como a era da informação, a evolução tecnológica passou a ditar as transformações 
históricas por meio delas mesmas, o que fez com que se esperassem cada vez mais mudanças no que tange às possibilidades da técnica e da tecnologia.

Por esse motivo, pode-se entender que, as tecnologias criadas pelo próprio homem, trazem benefícios ao mesmo, que necessita das tecnologias que cria e recria adaptando essas tecnologias as próprias mudanças da sociedade. Para explicar melhor, Mendes (2007) cita que o avanço tecnológico tem como proposito, beneficiar o bem-estar social, favorecendo os aspectos mediantes no trabalho e na educação, trazendo velocidade à informação e vantagens a grupos sociais que moram em localidades de difícil acesso.

Para tanto, essa evolução tecnológica citada por Mendes, que tem como intuito, facilitar a vida do homem, acaba gerando alguns impactos diferenciados sobre cada indivíduo da sociedade, seja ele, positivo ou negativo. Pois antes era o homem quem criava tecnologias e as adaptava as suas necessidades, e hoje o homem continua criando tecnologias, porém é o homem quem precisa se adaptar a essas tecnologias atuais, e isso causa o medo do novo, um medo de não conseguir seguir o mesmo ritmo dos avanços tecnológicos.

Diante disso, afirma Mendes (2007) que o medo não é de fato da tecnologia, mas sim das consequências que ela traz consigo, pela circunstância de parecer para algumas pessoas difícil de entender ou pela rapidez dos progressos tecnológicos que pode aparentar ser improvável de se alcançar. E isso acaba gerando desemprego e exclusão, por ser necessária a compreensão dessas tais tecnologias, para se informar e se comunicar, provocando mudanças na maneira de viver do indivíduo inserido na sociedade.

\section{A EDUCAÇÃO À DISTÂNCIA NO ENSINO SUPERIOR ATUAL}

\subsection{ORIGEM DA EAD NO MUNDO}

A Educação a Distância surgiu no começo da era industrial e conforme afirma Peres (2009), desde então, utiliza diversas metodologias e tecnologias trazendo a 
possibilidade de aprender por meio desse ensino. Com isso, pode-se dizer que a EAD surgiu para melhorar a educação e ampliar as possibilidades de estudar e obter novos conhecimentos, sendo a modalidade de estudo que possibilita a autonomia do aluno, em que ele mesmo organiza seus estudos. Desse modo, a EAD começou a se espalhar pelo mundo, abrindo muitas portas em diversos lugares.

Sendo assim, a educação à distância começou a se popularizar e a ganhar espaço em diversos lugares, como afirma Ribeiro (2010), em cuba no ano de 1979 na Faculdade de Havana, na EUA com mais de 100 universidades de cursos à distância, na Austrália onde existem muitos programas EAD que começam no ensino fundamental e vão até a pós-graduação, e outros países como a França, Alemanha, Espanha, México, Venezuela, Costa Rica, Índia, Nova Zelândia, China e outros.

O estudo a distância sempre está se atualizando de modo a correr junto com o tempo, rumo ao futuro, por ser uma modalidade de estudo, mutável e contraria a educação tradicional, sendo interativa e mudando suas ferramentas tecnológicas de acordo com as suas gerações, seja ela por correspondência, televisão, rádio ou computador. O surgimento da EAD também pode ser caracterizado, Segundo Ribeiro (2010), pelo modelo fordista e pós-fordista nos anos 1980, sendo da era industrial e tecnológica.

\subsubsection{TRAJETÓRIA DA EAD NO BRASIL (1891-2019)}

O ensino à distância teve sua origem no Brasil antes da Primeira Guerra Mundial, pois segundo Silva (2009, p.40), no ano de 1891 o Jornal do Brasil estava ofertando cursos por correspondência datilografada, com o intuito de transformar assim a vida da população brasileira, porém o ministro da época, José Seabra não acreditava na modalidade de ensino, com isso pronuncio a seguinte frase "O ensino chegou (no Brasil) a um estado de anarquia de descrédito que, ou faz-se a sua reforma radical, ou preferível será bani-lo de vez".

Já no século XX, o ensino a distância começa a ser manifestado através do rádio, com isso, Alves (2007, apud Silva, 2009) pontua que em 1923 um grupo liderado por Henrrique Morize e Roquete Pinto, fundou a rádio sociedade do Rio de Janeiro, no 
qual eram transmitidos conteúdos educativos. Daí em diante, começou um novo tempo no país, para dar início às mudanças que viriam a acontecer ao Brasil. Conforme Alvarenga (2012), na década de 1930 no Ministério da Educação, muitas mudanças ocorreram na educação brasileira.

Segundo Silva (2015) em 1932 ocorreu um movimento através dos Pioneiros da Educação, para que fosse desenvolvido o sistema escolar comum, de tal maneira que essa educação, distribuída nesse sistema, seria para que todos os brasileiros tivessem acesso à educação. Em seguida, no ano de 1936 Roquete Pinto doou ao ministério da educação sua emissora de rádio, para assim estabelecer no país a Rádio Ministério da Educação, para fins educativos como expõe Carvalho (2013).

De acordo com Diniz (2011), os programas mais relevantes de ensino supletivo surgiram através do ensino à distância por correspondência e rádio na década de 1940, depois da Reforma de Capanema, que caracterizava esse ensino como estudos particulares, que tinham como objetivo preparar os estudantes para exames presenciais.

Pela década de 1950 surge a Televisão educativa e na década de 1960 ocorreu à criação da Fundação Centro Brasileiro de Televisão Educativa, atualmente chamada de TVE, e ainda nessa década, foi criada também a Fundação Padre Anchieta, conhecida hoje como TV cultura de São Paulo e TVE do Maranhão. Logo em seguida na década de 1970, ocorreu o Projeto Minerva, que eram os cursos transmitidos pelos rádios daquela época conforme Duarte (2011).

Nas décadas de 1980 e 1990 houve um avanço na educação à distância no país, pois ocorreram muitos projetos de informática e linguagens estrangeiras, com isso muitos cursos passaram a ser oferecidos, como destaca Alves (2001, apud COSTA, 2014). Ainda na década de 1990 de acordo a LDB, no país "as bases legais para a modalidade de educação à distância foram estabelecidas pela lei oㅜ 9.394, de dezembro de 1996, que foi regulamentada pelo decreto n 5.622 " (BRASIL, 2007). 
Na década de 2000 conforme Pereira (2017), os cursos e matriculas no ensino a distância aumentaram significativamente. Como enfatiza Monteiro (2012), o destaque desse ensino também ocorre no Amapá, com a normatização da educação à distância pela LDB no ano de 1996 e também com a resolução n 36/07 - CEE/AP que estabelece normas para o funcionamento da modalidade de ensino no estado pela Legislação da EAD (BRASIL, 2007). Contudo Reis (2010, apud Monteiro, 2012) frisa que o Serviço Nacional de Aprendizagem Comercial (SENAC), já ofertava cursos à distância no estado desde 1992.

Já no inicio da década atual, a procura em cursos a distância no ensino superior é elevada, com isso a EAD começa a crescer na oferta e variação de cursos. Nesse sentido, como afirma Duarte (2011), o senso de 2010 da Associação Brasileira de Educação a Distância apontava cerca de 2.648.031 matriculados em EAD no país, nos 1.752 cursos oferecidos, entre credenciados e cursos livres.

Desde então a EAD ganha forças, até chegar aos dias atuais, no qual é a modalidade de ensino superior, em que os dados mostram o aumento tanto nos cursos ofertados quanto nas disciplinas presenciais. A partir disso, o site Extra Classe divulga que em 2019 os cursos de graduação na modalidade presencial, exceto de engenharia e da área da saúde, poderão dobrar a porcentagem de 20\% em aulas a distância para até $40 \%$, e essa medida está prevista na portaria $n^{\circ} 1.428$, no art. $3^{\circ}$, divulgada no dia 31 de dezembro de 2018, no Diário Oficial da União pelo Ministério da Educação (EXTRA CLASSE, 2019).

\subsection{CARACTERÍSTICAS DA EAD}

A modalidade de estudo a distância tem como características principais possibilitar o estudo a pessoas que vivem no interior ou no campo, onde estão distantes das cidades e dos polos universitários, e também pela autonomia que se ganha através do ensino à distância, onde o aluno aprende a prender. Nesse contexto:

A EAD se caracteriza como modalidade de ensino que promove situações de aprendizagem e desperta o interesse, tanto do sistema educativo, quanto do setor produtivo, podendo ser uma boa estratégia 
para suprir as necessidades de educação formal e continuada de profissionais de diversas áreas do conhecimento, dispersos em diferentes localidades geográficas. (ALVES, 2007, p. 36)

Isso se dá, através da possibilidade da educação à distância de proporcionar o ensino entre dois corpos físicos que mesmo distantes, são capazes de se comunicar, e nesse caso o professor é capaz de ensinar e o aluno é capaz de aprender, mesmo estando longe um do outro, o que demostra que o aprendizado não tem distância, fronteiras ou barreiras que impeçam que o conhecimento chegue à casa de cada um, não importa onde esteja, todo mundo pode aprender onde estiverem.

\subsubsection{PERFIL DO ALUNO DA EAD}

De acordo com Pereira (2015), na contemporaneidade, traçar as individualidades do aluno da Educação à distância não demanda apenas fatores sociais, demográficos e econômicos, mas também peculiaridades que fazem com que o aluno escolha e continue seu curso, pois as instituições se preocupam com a evasão. Diante disso, percebe-se, a necessidade de automotivação do aluno, para não desistir do curso, pois é o próprio aluno que controla sua aprendizagem, seu horário e seu modo de estudo. Dessa forma, Pereira afirma também que:

A realidade da $E A D$ tem especificidades próprias, como o gerenciamento do tempo, a responsabilidade diante do processo de aprendizagem e a adaptação ao próprio contexto de ambiente de aprendizagem. Quando o aluno se depara com esta realidade percebe que muitas vezes é incapaz de dar continuidade, perde a motivação, não acredita em seu potencial, além de sentir a responsabilidade diante de sua graduação. (PEREIRA, 2015, p. 44).

Por isso, a motivação e maturidade do aluno a distância são de suma importância para a conclusão do curso. Os alunos da Educação à distância são adultos, trabalham e possuem automotivação para conquistar aprendizado e crescer em sua carreira. Porém tais características variam de acordo com o perfil individual de cada aluno, pois existem aqueles alunos que conseguem se manter motivados até o final do curso, assim como existem aqueles alunos que perdem a força de vontade no meio do curso e acabam desistindo, como salienta Morini (2006). 


\subsubsection{AMBIENTE VIRTUAL}

Conforme Hack (2011), o ensino à distância não acontece fisicamente e nem delimita sincronia no tempo da realização das atividades, com isso os cursos possuem ambientes virtuais, que disponibilizam o material de estudo que pode ser acessado pelo aluno a qualquer momento e também há a possibilidade de imprimir esse material para o aluno estudar e transformar essas informações em conhecimento.

Dessa forma, percebe-se a praticidade que os ambientes virtuais de estudo proporcionam, tendo assim todas as ferramentas necessárias para que o aluno consiga se organizar da maneira mais flexível e dinâmica, tendo acesso a todos os conteúdos e suas atividades correspondentes, tanto como resultados de provas e atividades realizadas, sejam elas complementares ou obrigatórias.

Sendo assim, esse ambiente de aprendizagem pode ser usado de formas variadas, dependendo de cada estudante, e permitindo a liberdade do livre acesso as informações nele contidos. Os ambientes virtuais também podem ser caracterizados como comunidades virtuais e, como ressalta Linden (2011), esse ambiente se resume em uma comunidade virtual de diálogo didático on-line, com atividades que contribuem com o aprendizado do aluno, de modo que favorece a utilização diferenciada de cada aprendiz.

\subsection{TECNOLOGIA NO ENSINO SUPERIOR}

Os avanços tecnológicos fazem com que todo o percurso diário do ser humano, seja mais prático e interativo, portanto, na educação não é diferente e hoje a tecnologia é essencial para todos os níveis escolares. Porém no ensino superior, a tecnologia é o instrumento de estudo primordial, pois é a partir do processo de sistema virtual que acontece a educação à distância.

A EAD se manifesta através da tecnologia, como um marco em toda a história desse ensino. Através disso, pode-se dizer que essa prática de estudo ocorre, conforme Maia (2003), quando o professor está longe do seu aluno, e os meios tecnológicos os 
conecta. Com isso, compreende-se que a tecnologia, em qualquer época ou geração, é o que faz acontecer à educação à distância.

Nesse cenário, a tecnologia se torna a base da aprendizagem, que abrange um ensino interacionista que faz com que a EAD tenha mais qualidade e que o aluno tenha vontade de aprender sem que o ensino se torne maçante. Por isso, a educação a distância necessita de recursos tecnológicos adequados para se obter uma aprendizagem de qualidade.

\subsection{A EDUCAÇÃO A DISTÂNCIA DE GERAÇÃO EM GERAÇÃO}

Hoje a educação à distância é uma a plataforma de ensino que, juntamente com as tecnologias digitais, oferece ao aluno o conteúdo de um determinado estudo, de modo que o próprio aluno aprenda de maneira independente e livre como usar seu tempo e suas ferramentas de aprendizagem. Porém nem sempre foi assim, pois suas tecnologias e formas foram se modificando com o decorrer das décadas, no qual a educação a distância foi sendo moldada, sendo assim a EAD percorre por uma linha do tempo onde se encontra 3 gerações:

De acordo com Litto (2009), a primeira geração da educação a distância era feita por correspondência, o conteúdo era baseado de acordo com o curso escolhido pelo participante da modalidade, e esse material era enviado para o aluno semanalmente, no qual o desenvolvimento desse ensino teve forte ligação com o sistema de produção do fordismo.

A segunda geração, por sua vez, segundo Duarte (2011), ocorre juntamente com o surgimento da televisão, no qual a educação a distância vem por meio de telecursos, e também através de alguns cursos com o uso do rádio, onde a EAD perpassa pelos caminhos da mídia, com conteúdos tele transmitidos, por programas de televisão, com o objetivo e a metodologia, e também atores que contracenavam para demonstrar a situação que o professor colocava em suas aulas. 
Essa geração mostra alguns fatos que acontecem na vida cotidiana, através de telecursos, no qual o professor ensina o conteúdo. Em seguida, os atores demostram uma situação, baseada no conteúdo ensinado, para melhor entendimento do aluno, depois o professor dá uma conclusão ao conteúdo. Ainda hoje algumas emissoras de televisão fazem a transmissão dos programas de telecursos.

A terceira geração ocorre com as mudanças e novas tecnologias de informação e comunicação, de tal maneira que é marcada pela interatividade por meio dos ambientes virtuais, onde foi caracterizada, como ressalta Lopes (2007, p.55), como o "Estar Junto Virtual", ou seja, a comunicação que antes não existia, passou a ser possível, entre o professor e o aluno. Essa nova fase do ensino a distância é inovadora e essencial para o desenvolvimento e crescimento da modalidade de estudo, e dela são inspiradas as próximas gerações.

Alguns autores também afirmam a existência da quarta e quinta geração como destaca Litto (2009), sobre o surgimento da quarta geração que é caracterizada pela mudança provocada pelos avanços e pela rapidez da internet, que trouxe mudanças tanto na produção de materiais, quanto na distribuição mais eficaz e diferenciada, representada pelo ensino da "sociedade conectada". Sendo assim, o que aconteceu foi o aprimoramento das ferramentas já existentes na geração anterior.

De forma análoga, Duarte (2011) realça que a quinta geração é considerada atual, por suas atualizações de tudo que já existiu, sendo mais ampla e interativa. Ela é caracterizada pelo uso da internet, bem como o uso do ambiente virtual, que permite a livre opção do aluno de estudar através de vídeos, áudios, livros, jogos educativos e atividades simuladas, tendo a liberdade de se comunicar com o professor e tirar dúvidas através dos fóruns, tanto como o professor pode inserir atividades para o aluno também. Além das aulas tele transmitidas, que ocorrem em tempo real. Sendo assim, o aluno pode usufruir desses instrumentos de aprendizagem, da maneira mais acessível, de acordo com estilo de cada aluno.

Além disso, para Maia (2003, p. 73) a quinta geração é caracterizada também por "sistemas de respostas automáticas, ambientes de realidade virtual e comunicação 
por banda larga". No entanto, essas características já existem, porém não são trabalhadas em todas as instituições de ensino superior, pois ainda estão em desenvolvimento, principalmente o meio de realidade virtual. Atualmente, em Macapá, é disponibilizado o meio de realidade aumentada, para alguns cursos profissionalizantes no SENAI, mas no futuro possivelmente serão comuns esses meios de estudo nas instituições de ensino superior.

Ademais, diante da pesquisa efetuada, é possível perceber que mesmo com alguns autores afirmando a existência de 5 gerações da educação à distância, outros autores consideram que as características utilizadas na $4^{\circ}$ e $5^{\circ}$ gerações fazem parte da $3^{\circ}$ geração, que por sua vez é a geração atual.

\section{OS IMPACTOS QUE OS ALUNOS DA FACULDADE ESTÁCIO DO AMAPÁ ENFRENTAM COM A PLATAFORMA DIGITAL DO SISTEMA DO ALUNO}

\subsection{CARACTERIZAÇÃO DO PÚBLICO}

A pesquisa feita em campo, foi realizada com 50 alunos dos turnos da tarde e da noite, sendo que 5 alunos desse total foi realizada de maneira qualitativa e de forma quantitativa com os 50 alunos, com isso a metodologia usada foi quali-quantitativa. Os alunos que contribuíram com as respostas das questões qualitativas foram: A1 (aluna

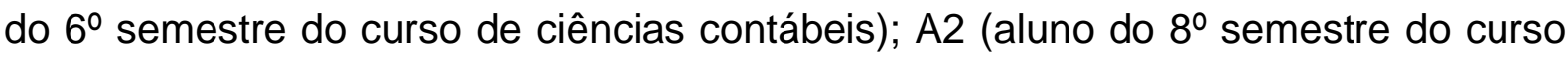
de pedagogia); A3 (aluno do 9o semestre do curso de direito); A4 (aluno do $8^{\circ}$ semestre do curso de administração); e A5 (aluno do $4^{0}$ semestre do curso de engenharia civil).

E os alunos que fizeram parte das questões de cunho quantitativo foram 50 , sendo: 27 do curso de direito, 6 do curso de engenharia civil, 9 do curso de pedagogia, 3 do curso de ciências contábeis e 5 do curso de administração.

Dentre os alunos do direito foram: 4 do $1^{\circ}$ semestre, 2 do $2^{\circ}$ semestre, 2 do $4^{\circ}$ semestre, 1 do $5^{\circ}$ semestre, 4 do $6^{\circ}$ semestre, 7 do $7^{\circ}$ semestre, 2 do $8^{\circ}$ semestre, 2 
do $9^{\circ}$ semestre e 3 do $10^{\circ}$ semestre. Do curso de Engenharia Civil foram: 2 do $4^{\circ}$ semestre, 3 do $6^{\circ}$ semestre e 1 do $7^{\circ}$ semestre. Do curso de Pedagogia foram: 4 do $4^{\circ}$ semestre e 5 do $8^{\circ}$ semestre. Do curso de Ciências Contábeis foram: 1 do $2^{\circ}$ semestre 1 do $4^{\circ}$ semestre e 1 do $6^{\circ}$ semestre. $E$ do curso de Administração foram: 1 do $4^{\circ}$ semestre, 1 do $5^{\circ}$ semestre, 2 do $6^{\circ}$ semestre e 1 do $8^{\circ}$ semestre.

\subsection{OS MAIORES DESAFIOS NO USO DO (SIA) E OS ASPECTOS POSITIVOS E NEGATIVOS}

Foi perguntado à entrevistada $A 1$ : Quais seus maiores desafios no uso do sistema de informações acadêmicas? E a aluna respondeu que: os maiores desafios no uso do sistema de informações acadêmicas, é nas aulas online porque às vezes elas abrem, às vezes não e quando abre tem professor que não fala direito, não tem uma metodologia, parece que ele saiu dos anos 2000, com slides de 30 anos atrás, e parece que ele está falando com um robô.

Diante da fala da aluna, é possível perceber que ela não está satisfeita com a metodologia das vídeos aulas, das disciplinas à distância, porque o sistema, apresenta algumas falhas e defeitos em sua metodologia, pois a aluna reclama das aulas, por serem antigas e desatualizadas.

E ainda foi perguntado a aluna: Quais os aspectos positivos e negativos nos $20 \%$ de disciplinas EAD que são obrigatórios? E a aluna respondeu que: o aspecto positivo ocorre quando as pessoas trabalham muito e não podem ir à aula e estuda em casa. Ou seja, a entrevistada acha positivo a questão de o aluno ter a comodidade de estudar em casa.

E os aspectos negativos a aluna respondeu que: Esses $20 \%$ é quase a metade de todas as disciplinas, então é mais negativo porque o professor não tem uma dinâmica boa, parece que não colocaram o professor preparado, porque em uma aula online a aluna teve o exemplo de uma professora que só falou do vestido dela, durante 30 minutos de aula. No contexto da resposta da aluna, entende-se que a entrevistada não se conforma com a quantidade de disciplina, pois considera que tem muitas 
disciplinas online. E ainda ficou inconformada com uma das aulas online, em que a professora, fugiu do assunto e ficou falando do seu vestido.

O entrevistado A2 não tem nenhum desafio no uso do sistema de informações acadêmicas. O aluno não vê nenhum aspecto positivo quanto aos 20\% EAD que são obrigatórios, pois ele diz que é acostumado com o ambiente virtual e gosta do ambiente virtual do sistema, mas detesta a ideia de ter que estudar online, assistir aulas online, e fazer leituras de livros online, porque prefere o físico.

Enquanto o entrevistado A3 diz que o seu maior desafio é quando o sistema trava, quando está próximo do período de provas. Para o aluno: os aspectos positivos desse sistema, na visão desse aluno é a questão do ensino, onde tem muita matéria boa para estudo à distância e os aspectos negativos é que muitas matérias que eram presenciais se tornaram online e isso prejudicou um pouco os alunos, porque tem alguns alunos que às vezes não assistem a vídeo aula, não estuda e isso, no desenvolvimento no futuro, vai ser prejudicial à carreira profissional.

Em seguida, para o aluno A4, seu maior desafio no sistema foi no semestre passado porque ele não estava conseguindo assistir as aulas online, porque não abriam. Em questão dos aspectos positivos para o aluno é a comodidade de ter alguns dias vagos, de não ser todo o dia na faculdade e os aspectos negativos é a falta de interatividade com o professor presencial que acaba causando o relaxamento de só estudar para o dia da prova.

E o aluno A5 diz que seu maior desafio no uso do sistema é para achar o conteúdo interativo que os professores postam no sistema, porque às vezes é complicado de encontrar e a biblioteca virtual, também é complicado, na questão de achar livros para fazer reserva e até para enviar relatórios ou trabalhos pelo SIA.

Seu aspecto positivo nos $20 \%$ EAD, de acordo com a opinião do aluno, é que não precisa ir a outra plataforma para estudar, pois já tem o conteúdo específico das disciplinas, para poder fazer o estudo complementar, então não precisa ficar pesquisando muito, nem perdendo muito tempo, e tem muitos livros na biblioteca 
virtual. $E$ os aspectos negativos é que às vezes esse ensino, deixa o aluno um pouco disperso, porque na educação à distância é difícil entender melhor o conteúdo, porque na sala dá para tirar dúvida com o professor e pedir para ele explicar novamente de outra forma mais clara.

\subsection{REPROVAÇÃO EM DISCIPLINAS À DISTÂNCIA E OS IMPACTOS DOS ALUNOS DIANTE DO SISTEMA DE INFORMAÇÕES ACADÊMICAS E SUAS FUNÇÕES}

\subsubsection{REPROVAÇÃO EM DISCIPLINAS À DISTÂNCIA}

Os motivos de reprovação nas disciplinas EAD, dos 50 alunos entrevistados, 14 reprovarão, como se pode observar no gráfico 01 , os $28 \%$ foram os que reprovarão em disciplinas online e seus principais motivos foram: o desanimo de assistir aulas, dificuldade de abrir o sistema e se organizar para estudar as disciplinas e a falta de compreensão de alguns termos também.

Gráfico 01: Reprovação nas disciplinas online da Faculdade Estácio do Amapá.

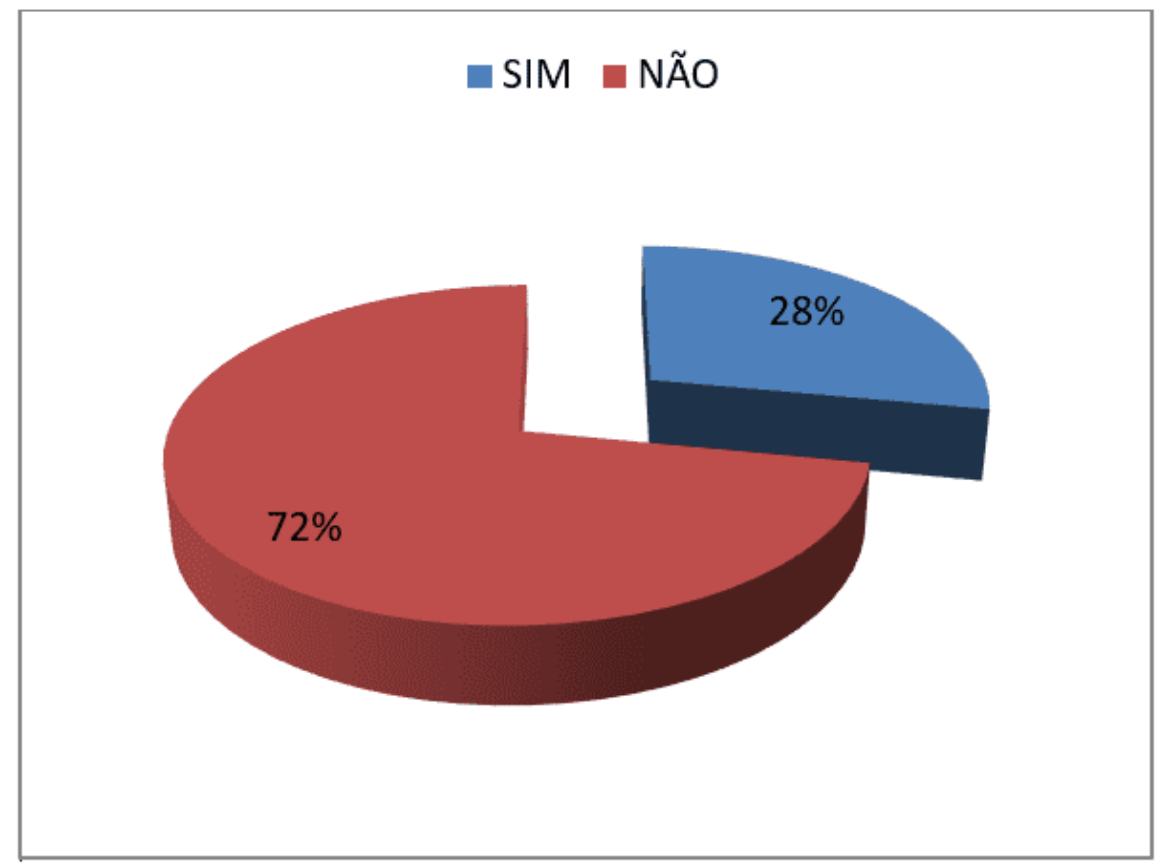

Fonte: a autora (2019) 
Outros motivos que levaram a reprovação, colocados pelos alunos, é quando o aluno passa na prova, porém não tem a porcentagem mínima no sistema para passar, por esse motivo reprova. Como também a falta de interesse de assistir as aulas, bem como por motivos de doença, ou porque não tem um bom desempenho, por não entender o conteúdo ou porque alguns alunos não conseguem acessar a plataforma porque o sistema trava. Contudo, é possível percebe que a maior parte dos alunos entrevistados, do total de 36 alunos, referentes aos $72 \%$ do total, de 50 alunos, não reprovou em nenhuma matéria online.

\subsubsection{IMPACTOS POSITIVOS E NEGATIVOS DA EAD}

Os alunos que fazem parte dos $54 \%$ no gráfico 02 , que consideram que o sistema gera impactos positivos, destacam que o sistema tem facilidade ampla e flexibilidade, para entender sobre o assunto estudado nas aulas à distância. Porque o sistema da Estácio é um dos melhores sistemas acadêmicos, principalmente a biblioteca que dá para encontrar bastante livro e estudar um pouco mais. Ele só fica às vezes fora do ar. Com isso, destaca Hack (2011), que a interação por meio de ambientes virtuais é uma vantagem na aprendizagem do ensino à distância, pois concilia flexibilidade e independência.

Gráfico 02: Impactos positivos e negativos da EAD.

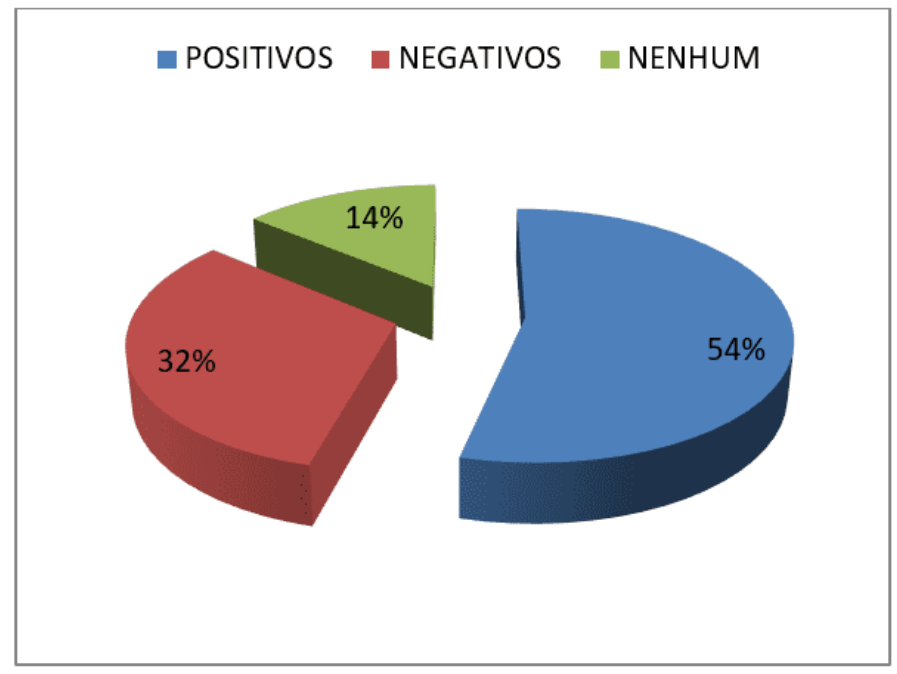

Fonte: a autora (2019) 
E os alunos evidenciam também, que os professores são muito bons, a estrutura da faculdade é boa, e o ensino é muito bom, pois os professores são bem preparados. Porque tem acesso a um material que é online e isso facilita até na entrega de atividades avaliativas. Pois facilita a vida acadêmica do aluno, com as possibilidades de agendamentos, questões de horários e boletos. Porque ele é fácil, prático e acessível. Pela questão do material, que tem bastante recurso, então fica mais fácil para adquirir conhecimentos, por ser uma plataforma que possibilita uma troca de informações.

Esses alunos ressaltam que o SIA é uma plataforma boa, que a cada ano vai se inovando em novas ferramentas, para serem utilizadas, e a faculdade sempre pensa em várias formas de investir em mão de obra, equipamentos e estrutura e sempre fazem reuniões, com os representantes de turma, para verificar quais as melhores soluções em investimentos e melhoria, então a faculdade sempre está interessada no melhor aprendizado do aluno. E também é positivo, porque o sistema complementa informações das disciplinas presenciais.

Os alunos que fazem parte dos $32 \%$ que consideram que o sistema gera impactos negativos, diante da educação à distância, ocorrem segundo os alunos por causa da falta de motivação para estudar, e das dúvidas que surgem na hora da disciplina online que só podem ser respondidos se for atrás, na internet. Por causa da falta de organização, que gera até reprovação nas disciplinas, e em um dos casos relatados, a aluna não conseguiu organizar o seu horário, e perdeu a prova porque era no horário de Brasília, então a aluna disse que isso não foi orientado corretamente e ela acabou pagando novamente a disciplina.

Bem como, os alunos enfatizaram que colocaram matérias essenciais à distância, e nessa modalidade de ensino, nunca se foca tanto como se fosse presencial, porque não há tanta dedicação. Pois, ele tem muito que melhorar, porque falha muito e não tem como o professor tirar dúvidas nas aulas online, porque não tem um professor presente. Uma vez que com um sistema de disciplinas à distância, não tem aproveitamento da matéria, porque é só fazer 3 ou 4 atividades para passar nas 
provas. $\mathrm{E}$ os outros $14 \%$ dos alunos não identificam nenhum aspecto positivo ou negativo na educação à distância.

\subsection{OS MOTIVOS QUE DIFICULTAM O MANUSEAMENTO DO SISTEMA}

De acordo, com as analises, foi possível perceber que 29 dos 50 alunos entrevistados, correspondentes aos $58 \%$ do total, não tem dificuldade no manuseamento do sistema. Em seguida, é possível visualizar no gráfico 03 que 17 alunos correspondentes aos $34 \%$ do total, responderam outros, no qual, esses outros foram justificados por conta da baixa qualidade da internet, a falta de informações ou suporte da faculdade, a falta de motivação, a falta de disposição, a manutenção do sistema, quando fica dando erro no sistema e não dá para acessar o sia, a falta de disponibilidade, ou quando o sistema falha ou fica lento, e só fica carregando e nunca entra na página do sistema acadêmico.

Gráfico 03: Dificuldades no manuseamento do sistema.

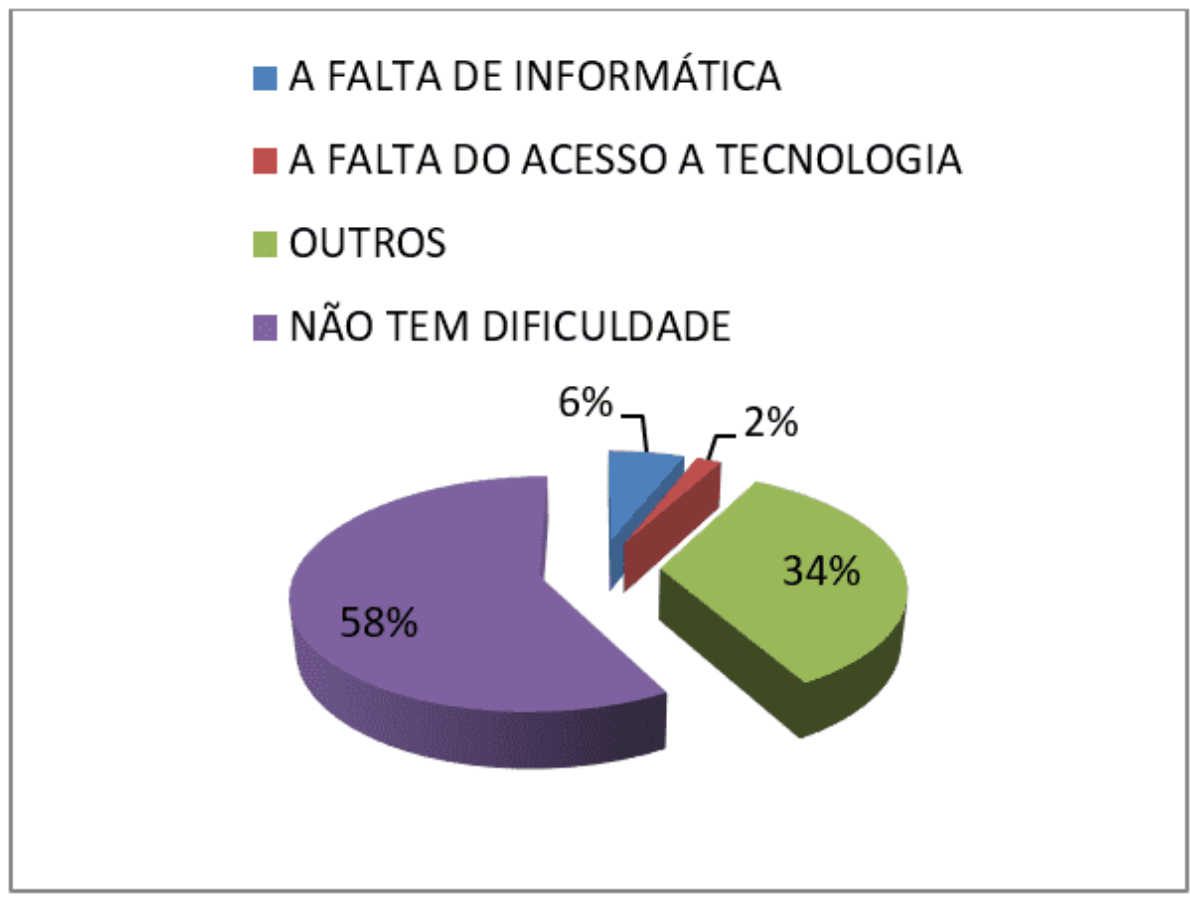

Fonte: a autora (2019) 
Logo em diante, vem a falta de informática que é a necessidade de 3 alunos dos 50 , correspondentes aos $6 \%$ do total, que destacam que essa necessidade existe porque as vezes os alunos encontram dificuldades que podem ser resolvidas com um bom curso de informática ou informação mesmo, e também a questão que nem tudo que está no sia é auto explicativo, precisa de outra pessoa para explicar como é que faz, contando com os vídeos no youtube que ensinam a fazer algumas coisas no sistema, porque alguns ramos dele, não são auto explicativos, como deveriam ser. E por fim, o ultimo aluno entrevistado, tem a necessidade da falta do acesso à tecnologia que é a falta do acesso a computador.

\section{CONSIDERAÇÕES FINAIS}

Neste trabalho de conclusão de curso, foi possível, entender sobre a educação à distância inserida na vida acadêmica dos alunos da Faculdade Estácio do Amapá, no uso do ambiente virtual, como meio de tecnologia de informação e comunicação. Dentre seus impactos tanto positivos quanto negativos existentes.

$\mathrm{Na}$ primeira parte da pesquisa, foi possível, compreender os conceitos sobre o surgimento da tecnologia e das TICs, assim como suas características por meio da tecnologia de informação e comunicação, discorrendo sua utilização pelo homem, na educação, no trabalho e suas transformações. No segundo tópico foi possível entender a origem da EAD no mundo, bem como a sua trajetória no Brasil desde 1891, até chegar aos dias atuais. Ademais, também foi, destacado neste tópico, as características da educação à distância, o perfil do aluno desta modalidade de estudo, perpassando pelo ambiente virtual, a tecnologia no ensino superior e as gerações deste ensino.

E no ultimo tópico foi feita a análise da pesquisa de campo, no qual buscou-se responder, quais impactos os alunos da Faculdade Estácio do Amapá enfrentam com a plataforma digital do sistema do aluno, que pode-se perceber que, esses impactos são, conforme a maioria dos entrevistados, os $54 \%$ do total, tem impactos positivos apesar dos desafios existentes. E esses alunos destacam que o SIA é um dos melhores sistemas acadêmicos, apesar de ficar fora do ar às vezes, ele facilita a vida 
do aluno. Esses alunos consideram o SIA um sistema flexível, acessível e prático. Além de complementar as informações de disciplinas presenciais com livros e material postado pelo professor.

Ademais $32 \%$ do total de entrevistados têm impactos negativos diante do ambiente virtual, por conta da desmotivação em acessar o ambiente para assistir aulas e estudar, porque o sistema falha muito, por não ter um professor para tirar dúvidas, porque não tem aproveitamento das matérias. E os 14\% restantes, representam os alunos que não tem nenhum tipo de impacto diante do ambiente virtual.

Com isso é possível perceber que mesmo com os desafios, a maior parte desses alunos considera que o sistema de informações acadêmicas proporciona aos alunos impactos positivos, pois esses alunos consideram que é um dos melhores sistemas acadêmicos, porque ele é prático e acessível, como também facilita a vida do acadêmico, em diversos setores, tanto nas disciplinas, quanto em informações sobre a situação do aluno na faculdade. Mesmo com a baixa qualidade da internet, citada pelos alunos e também algumas falhas do próprio sistema.

\section{REFERÊNCIAS}

ALVARENGA, A. G. S. Os intelectuais da educação da década de 1930 vinculados a comissão de censura cinematográfica. In: XI SEMINÁRIO NACIONAL DE ESTUDOS E PESQUISAS "HISTÓRIA, SOCIEDADE E EDUCAÇÃO NO BRASIL". 2012. João Pessoa. Anais... Universidade Federal da Paraíba, 2012. p. 253 - 254.

ALVES, P. F. Um estudo sobre as alternativas de desenvolvimento profissional dos professores frente a modalidade de Educação à distância, baseada em tecnologias da internet. 2007. 130 f. Dissertação de mestrado - CEFET - MG, Belo Horizonte, 2007.

ALVES, T. A. S. Tecnologia da informação e comunicação (TIC) nas escolas: da idealização à realidade. 2009. 134 f. Dissertação de mestrado - Universidade Lusófona de Humanidades e Tecnologias, Lisboa, 2009. 
BRASIL. Resolução no 36/07 CEE /AP. Legislação da EAD, 20 jun. 2007. E-book.

CARVALHO, A. H. A evolução histórica da educação a distância no Brasil: Avanços e retrocessos. 2013. 36 f. Monografia. Universidade Tecnológica Federal do Paraná, Medianeira, 2013.

CASTILHO, L. B. O uso da tecnologia da informação e comunicação (TIC) no processo de ensino e aprendizagem no ensino superior brasileiro. 2014. 79 f. Dissertação de Mestrado - Universidade Fumec, MG, Belo Horizonte, 2014.

COSTA, M. L. F. ZANATTA, R. M. et al. Educação a distância no Brasil: aspectos históricos, legais, políticos e metodológicos. 2014. 130 f. Eduem, Maringá, 2014.

DINIZ, E. C. LINDEN, M. M. G. V. FERNANDES, T. A. Educação a distância: coletânea de textos para subsidiar a docência on-line. 2011. 205 f. Editora Universitária - UFPB, João Pessoa, 2011.

DUARTE, Z. M. C. Educação a distância (EAD): estudo dos fatores críticos de sucesso na gestão de cursos da região metropolitana de Belo Horizonte na visão dos tutores. 2011. 82 f. Dissertação de Mestrado Universidade FUMEC, Belo Horizonte, 2011.

EXTRA CLASSE. Graduações poderão ter até 40\% de EAD. Disponível em: <https://www.extraclasse.org.br>. Acesso em: 23 de fevereiro de 2019.

HACK, J. R. Introdução à educação a distância. 2011. 126 f. LLV/CCE/UFDSC. Florianópolis, 2011.

HARA, C. L. Home office e as tecnologias de acesso remoto. 2011. 41 f. Monografia, FATEC, São Paulo, 2011.

KENSKI, V. M. Educação e tecnologias: O novo ritmo da informação. 2012. $141 \mathrm{f}$. Papirus Editora, São Paulo, 2012.

LITTO, F. M. FORMIGA, M. Educação a distância: o estado da arte. 2009. 479 f. Pearson. São Paulo, 2009. 
LOPES, M. S. S. Avaliação da aprendizagem em atividades colaborativas em EAD viabilizada por um fórum categorizado. 2007. 168 f. Universidade Federal do Rio de Janeiro, Rio de Janeiro, 2007.

MAIA, M. C. O uso da tecnologia de informação para a educação a distância no ensino superior. 2003. 294 f. FGV-EAESP. São Paulo, 2003.

MENDES, F. R. Tecnologias e a construção do conhecimento na sociedade da informação. 2007. 85 f. Dissertação de Mestrado - Universidade Estadual de Londrina, Londrina, 2007.

MONTEIRO, A. R. S. Desafios da EAD no estado do Amapá. 2012. 49 f. Monografia. Universidade Federal do Amapá, Macapá, 2012.

MORINI, A. M. Um estudo sobre o perfil do aluno do ensino à distância. 2006. 43 f. Monografia. UnisulVirtual, Palhoça, 2006.

PERES, A. L. Um modelo de aferição de usabilidade dos diferentes personas em ambientes virtuais de aprendizagem no contexto da educação à distância a partir de um estudo de caso do sistema UAB/UFAL. 2009. 163 f. Dissertação de mestrado Universidade Federal de Alagoas, Maceió, 2009.

PEREIRA, G. B. B. O estudante da EAD (Educação à distância): Um estudo de perfil e interação geracional. 2015. 133 f. Dissertação de Mestrado - Universidade Metodista de São Paulo, São Bernardo do Campo, 2015.

PEREIRA, M. F. R. MORAES, R. A. TERUYA, T. K. et al. Educação a distância (EAD) reflexões críticas e práticas. 2017. 275 f. Navegando Publicações, Uberlândia, 2017.

RIBEIRO, E. L. Uma avaliação da importância da gestão da qualidade na prática da educação à distância. 2010. 148 f. Dissertação de mestrado - Universidade Paulista, São Paulo, 2010. 
SANTOS, A. C. B. A utilização das TIC como meio facilitado do processo ensino aprendizagem nas series iniciais do ensino fundamental. 2014. $62 \mathrm{f}$. Monografia, Universidade de Brasília - DF, Brasília, 2014.

SILVA, M. B. N. Escola nova na "Página da Educação" (1930-1933): navegando nas palavras de Cecília Meireles no "Diário de Notícias". 2015. 161 f. Tese de doutorado. Universidade Federal de Uberlândia, Uberlândia, 2015.

SILVA, W. V. K. M. Uma revisão sistemática das publicações cientificas sobre políticas em educação à distância no Brasil. 2009.156 f. Dissertação de Mestrado Universidade do vale do Itajaí, Itajaí, 2009.

SOUZA, M. GIGLIO, K. Mídias digitais, redes sociais e educação em rede: Experiências na pesquisa e extensão universitária. São Paulo: Blucher, 2015.

VINHA, T. F. Tecnologia, trabalho e educação: perspectivas, estratégias e trajetórias dos jovens no mercado de trabalho informacional. 2007. 248 f. Dissertação de Mestrado - Universidade de São Paulo, São Paulo, 2007.

Enviado: Junho, 2020.

Aprovado: Julho, 2020. 